\title{
Wolves at the door: Musical persuasion in a 2004 Bush-Cheney campaign advertisement ${ }^{1}$
}

\section{Matthew Killmeier \& Paul Christiansen}

MedieKultur 2011, 50, 160-180

Published by SMID | Society of Media researchers In Denmark | www.smid.dk The online version of this text can be found open access at www.mediekultur.dk

Many journalists and scholars overlook the discursive role of music in TV political advertisements. But we argue that music is a potent means of political persuasion. Music in advertisements is determinative; all other elements-images, voiceovers, sound effects, written text, and so on-are circumscribed by the music and interpreted in relation to it. Music determines an advertisement's character through framing and underscoring; musical frames establish interpretative categories and generate expectations, while underscoring comprises music that closely coordinates with images and voiceovers to form a persuasive aesthetic and rhetorical unity. A close reading of a 2004 Bush-Cheney advertisement applies this theory of frames and underscoring to explain the advertisement's effectiveness. Without music, the advertisement would not only fail to persuade, it would also make no sense.

Critics often remark that political television advertisements elevate image over substance. Images indeed are a seminal part of U.S. political persuasion, but they are intertwined with substance in advertisement discourses as some critics are beginning to recognize. However, critics largely overlook advertisements' sonic elements. Paramount among them is music, which bridges images, i.e., the poetic, and substance, i.e., the logical. Advertisements persuade on multiple levels, and they work as persuasive entities because of music. 
Below, we advance this claim through a critical analysis of a 2004 Bush-Cheney campaign advertisement, "Wolves". ${ }^{2}$ The advertisement epitomizes the melding of image and substance, makes a visceral impression, and conveys a strong message in a competitive campaign. "Wolves" deftly combines poetic and logical persuasion into a seamless whole through music. We argue that music is determinative in political advertisements. Before presenting our argument, we first summarize some of the scholarship on music in advertising.

\section{Music in advertising}

Up to now, scholars writing about political advertisements have privileged images and language above music. These studies convey the impression that music in an advertisement is something of an afterthought, an innocuous accompaniment to the advertisement's visual and textual elements. However, there is relevant research that foregrounds the role of music in advertising, political and otherwise.

A recent foray into this area is Nicolai Graakjær's (2006) article on musical meaning in television commercials, as exemplified in a spot for Riberhus cheese. In the article, Graakjær describes the complexities and potential problems of using pre-existing music to advertise products, and he points out the strong need for more research into the use of music in television advertising. Gerard Tellis (2003) addresses the recent and financially felicitous marriage of popular music to television commercials. Sponsors attempt to co-opt popular songs, artists, and genres in order to appear hip or cool (Frank 1997). David Huron (1989) suggests that music can be used to target certain demographic, psychographic, and political groups, tapping already established articulations between musical genres, styles, and social collectives. Similarly, it can facilitate the establishment of authority, the determination of a character's ethos. Here music is used as "a very effective nonverbal identifier" that connects the target audience with the appropriate group (i.e., race, sex, age, and socioeconomic class/status) (p. 568). Melodies, timbres, rhythms, and so forth target audiences through an established network of historical connotations (p. 571).

Nicholas Cook (2001) claims that music ascribes attributes to products, but that it is also affected by other signifiers (verbal, aural, and visual). "If the music gives meaning to the images, then equally the images give meaning to the music" (Cook 2001, p. 8). Working on a "subverbal, almost subliminal" level, music helps to connect a product with signification from outside and can make absurd arguments seem plausible (p. 20). As we propose below, political advertising uses music in a similar fashion to market candidates.

Political scientist Ted Brader's (2006) empirical research found music to be an effective element in campaign advertisements that appeal to fear. Fear appeals contributed to the likelihood of political novices withdrawing from political participation, while they inspired the politically initiated to act. Overall, "fear ads elicited the highest level of anxiety," and "menacing music and imagery strengthened reactions of fear and anxiety to the 
negative message" (p. 86). In a similar vein, Carol Krumhansl's (1997) experimental research found that subjects could identify fear within particular pieces of music. While listening to excerpts identified as "fearful music," subjects experienced significant changes in pulse rate and amplitude. ${ }^{4}$

\section{Music is determinative}

In this article, we consider music not only as a key element in the construction of an advertisement, but as determinative. In asserting this claim, we mean that all other elements in an advertisement-images, voiceovers, sound effects, written texts, and so on-are circumscribed by the music and interpreted in relation to it. In most cases, all the parts work together to form a unity. If the other elements seem incongruous with the music, we may read the advertisement as ironic or sardonic in tone. But music undergirds everything. ${ }^{5}$

We define determinative as Raymond Williams does: setting limits and exerting pressures (Williams 1977). Williams states that ideology works not through causality, but rather through circumscription. Ideology sets limits of reasonability or viability, and canalizes interpretations or conclusions. Williams reclaims determination as a critical concept that encompasses structure without precluding agency. In other words, interpretation is not prefigured, nor are audiences predestined to reach certain conclusions. People can interpret advertisements in numerous ways. However, determination lessens the likelihood of misinterpretation, and is therefore imperative in media texts, especially advertisements.

\section{Framing}

We posit two related but discrete functions for advertisement music: framing and underscoring. Advertisers strive to gain our attention immediately and to leave a powerful impression at the end. Using genre as aural shorthand of a fashion, musical frames in advertisements determine parameters. Musical frames establish interpretive categories and generate expectations for what is to follow-for instance, humor or reverence. Frames initiate a pattern that audiences anticipate will develop in a certain fashion.

Framing has a particular and well-established valence in scholarship on political discourse. George Lakoff (2004) has written of conceptual determination based on linguistic differentiation-how language is used to determine the terms of debate. Often we are unaware of how words and phrases strongly color our perceptions of candidates and issues in the political doxa.

Despite similarities, musical framing is a markedly different process than linguistic framing. As difficult as it is for candidates to counter linguistic framing by their opponents, music is even harder to deal with. Musical framing is largely surreptitious, as most people are not musically literate enough to identify it. Ignorance of music's capacities allows people to perceive it as sonic background, unaware of its determinative role. Furthermore, when 
music is addressed at all, it is largely in poetic rather than discursive terms. Most people do not consider music a means of persuasion, and this magnifies its framing power. Of course music is poetic, but it can also be used discursively, as many advertisements, films, and TV programs attest. It guides us to interpret audio-visual texts within certain parameters, and it generates expectations. Music frames through limning the aural space and, consequently, the rhetorical discourse. It brings together what would otherwise be disparate, discrete elements into a persuasive package.

Musical frames construct a poetic discourse. Political advertisements increasingly mount a poetic discourse alongside their logical one. The poetic discourse-an impressionistic portrait, vignette, parable or short story-is constructed through images and sound that complement, but many times do not replicate, the logical discourse. Music propels the seamless unfolding of a story that positions citizens as audiences of dramatic narratives. For instance, an attack advertisement may feature a logical discourse that claims a candidate will raise taxes, offering a record of his or her votes as support. That advertisement may provide a poetic discourse that conveys the candidate as monstrous, through grainy, black and white images and music that generically and stylistically connotes horror films. Ideally, the audience is left with the impression that the candidate is threatening, and it is music that convinces.

The most persuasive elements of many contemporary political advertisements, including "Wolves," lie in their poetic realm, particularly music. Such advertisements present an often facile logical argument, but also a sophisticated, sonic-poetic argument that escapes the scrutiny of audiences and journalists. Indeed, "Wolves" was criticized by FactCheck. org for its "'direct appeal to fear' that 'misleads voters' by distorting Kerry's record" (Montgomery 2004). Unfortunately, such campaign "truth-squads" overlook the advertisement's poetic discourse, where its most persuasive means lie. Most voters and journalists "often are ill-equipped to deal with non-discursive appeals" such as those made through music (Sproule 1994, p. 334). Music's persuasive role is thus not subject to rhetorical scrutiny. Advertising in general has long striven to seem non-discursive, often doing so by invoking or emulating popular culture. More recently, advertising's goal has been to merge with culture (Jhally 1990; Klein 1999). Political advertising has followed suit.

Music primarily frames through genres, which are "shared conventions" (Berger 1992, p. xi) that link music, meaning, culture and listeners. One of music's main persuasive functions lies in its capacity to import signification into the advertisement through genre. Nelson and Boynton (1997) argue that popular meanings in advertisements are elicited successfully with popular musical genres. Music can also serve to frame "visual meanings" (p. 100). Similarly, Richardson (2003) asserts that genres serve as frameworks that bring in meanings from larger cultural fields. Genres thus connote, opening up an entire range of potential meanings, which arise from music's capacity to add color, convey a particular mood, or elicit emotion. Relative to visual or verbal expression, music condenses a great deal into a 
few notes: its connotative ability is economical but capacious. In just a few seconds, music establishes mood and sets expectations.

Denotatively, genres work to define something clearly and effectively. For instance, horror music can define opponents, their policies, or ideology as terrifying. Frequently, music used in fear advertisements "features tension-raising instrumentals full of minor chords, ominous rhythms, and discordant tones" (Brader 2006, p. 10). Of course, the music is complemented by visual and verbal material that reinforce it, such as "grainy, black-andwhite images or dark and muted colors" (Ibid.). However, as images are denotatively weak and require grounding lest they be interpreted too broadly, musical genre is essential in advertisements. The images in "Wolves," for example, might be interpreted as signifying wilderness. Therefore, music plays an imperative denotative role in signifying the wolves as threatening. One use of genre is to establish difference that an advertisement's visuals lack.

\section{Underscoring}

Occurring over time within the parameters set by the musical frame, underscoring is music closely coordinated with images and any voiceover or sound effects to form an aesthetic and rhetorical unity that persuades efficiently and effectively. Key words in a voiceover are often articulated with specific musical events that enhance the words' importance. Underscoring describes the way music is arranged within the parameters set by musical framing. It is achieved through style, the particular organization of musical elements in the advertisement.

Framing and underscoring are ways of organizing musical signification. Musical frames delimit signification at the beginning of advertisements by establishing a musical genre. Once the genre is established, meaning is implied and developed within the advertisement's underscoring, moment by moment through stylistic organization. At the end of an advertisement, a concluding frame-often an intensified version of the beginning frameleaves the audience with an advertisement's strongest aural impression, one that is meant to imbed itself in their subconscious. Overall, music creates a dialectical gestalt that transcends its parts and integrates the advertisements' logical and poetic dimensions; this totality comprises the overall impression an advertisement makes, which is determined by its music.

\section{"Wolves"}

We analyze three discrete sections in "Wolves." In part, we do this to sharpen the focus, but the rhetorical construction of "Wolves" also justifies this approach. The voiceover text with the progression of images can be clearly divided into three roughly equal parts, which we have designated Beginning, Middle, and Ending. (This division is reflected in Table 1.) Each section has its own distinct rhetorical and narrative function. Below we will treat each section individually, detailing how music works with other elements in the advertisement. Of course, some overlap exists along these borders, and in important ways the advertisement 
is an effective, unified totality. In our conclusion, we will address the advertisement as a unified whole and draw conclusions from our interpretations.

The music in "Wolves" belongs to the horror genre; it is intended to frighten audiences into voting for the Bush-Cheney ticket based on the implied assumption that only they could keep the American public safe. We hear primal drum beats that seem like irregular heartbeats; we hear a shrill alarm whistle signaling danger; we hear plaintive, mournful strings that emote; and throughout we hear low, rumbling drones that disturb and distress us. The soft but extreme dissonance at the very end of the advertisement completes the feeling of dread. In the analysis that follows, we describe the effect of the advertisement's music in conjunction with the visual and textual elements.

\section{Table 1:}

Representation of Bush-Cheney 2004 campaign advertisement "Wolves" in graph form

Beginning

\begin{tabular}{|c|c|c|c|c|}
\hline SHOTS & $\begin{array}{l}\text { VOICEOVER } \\
\text { (stressed words } \\
\text { in bold) }\end{array}$ & $\begin{array}{l}\text { MUSIC } \\
\text { (electronically } \\
\text { generated) }\end{array}$ & SOUND F/X & TEXT \\
\hline \multirow[t]{2}{*}{$\begin{array}{l}\text { Establishing shot: } \\
\text { bird's eye view } \\
\text { of dark forest } \\
\text { shrouded in fog }\end{array}$} & & $\begin{array}{l}\text { FRAMING: Low } \\
\text { flute F drone, } \\
\text { explosive, attention- } \\
\text { getting drum beat, } \\
\text { then soft drum beat }\end{array}$ & & \\
\hline & IN AN & & $\begin{array}{l}\text { Rustling leaves, } \\
\text { snapping twigs }\end{array}$ & \\
\hline $\begin{array}{l}\text { Close-up of conifer } \\
\text { in sharp focus, } \\
\text { shallow depth } \\
\text { of field; then } \\
\text { foreground blurs, } \\
\text { bringing back- } \\
\text { ground forest into } \\
\text { focus }\end{array}$ & INCREASINGLY & & & \\
\hline $\begin{array}{l}\text { Long, downward } \\
\text { soft focus pan of } \\
\text { forest, lens flare } \\
\text { from sun shining } \\
\text { through forest }\end{array}$ & $\begin{array}{l}\text { DANGEROUS } \\
\text { WORLD, EVEN }\end{array}$ & $\begin{array}{l}\text { UNDERSCORING: } \\
\text { Flute g" }(\mathrm{C} 5)^{*}\end{array}$ & $\begin{array}{l}\text { Rustling leaves, } \\
\text { snapping twigs }\end{array}$ & \\
\hline \multirow[t]{2}{*}{$\begin{array}{l}\text { Split-second image } \\
\text { of wolf's face, } \\
\text { then shot of wolf } \\
\text { running from right } \\
\text { to left }\end{array}$} & $\begin{array}{l}\text { AFTER THE } \\
\text { FIRST TERRORIST } \\
\text { ATTACK ON }\end{array}$ & $\begin{array}{l}\text { Harp f" (C5) to } \\
\text { b-flat" (C5); flute } \\
f^{\prime}(C 4)\end{array}$ & & \\
\hline & AMERICA & $f^{\prime}(\mathrm{C} 4)$ continues & & \\
\hline
\end{tabular}




\section{Middle}

\begin{tabular}{|c|c|c|c|c|}
\hline SHOTS & VOICEOVER & MUSIC & SOUND F/X & TEXT \\
\hline \multicolumn{5}{|l|}{$\begin{array}{l}\text { Medium soft focus } \\
\text { POV of forest, } \\
\text { panning back and } \\
\text { forth }\end{array}$} \\
\hline & $\begin{array}{l}\text { JOHN KERRY AND } \\
\text { THE LIBERALS } \\
\text { IN CONGRESS }\end{array}$ & $\begin{array}{l}\text { Two low drum } \\
\text { beats }\end{array}$ & & \\
\hline $\begin{array}{l}\text { Medium sharp } \\
\text { focus shot of wolf } \\
\text { walking upward } \\
\text { from right to left } \\
\text { through ferns }\end{array}$ & & & $\begin{array}{l}\text { Snapping twigs as } \\
\text { wolf moves }\end{array}$ & \\
\hline $\begin{array}{l}\text { Medium soft focus } \\
\text { shot of forest } \\
\text { backlit by sun, pan } \\
\text { from upper left to } \\
\text { lower right }\end{array}$ & VOTED TO SLASH & $\begin{array}{l}\text { Strings c" (C5) and } \\
\text { g" (C5), soft drum } \\
\text { beat }\end{array}$ & & \\
\hline $\begin{array}{l}\text { Close-up soft focus } \\
\text { of half of wolf's } \\
\text { face, its jaws } \\
\text { menacingly open }\end{array}$ & $\begin{array}{l}\text { AMERICA'S } \\
\text { INTELLIGENCE } \\
\text { OPERATIONS }\end{array}$ & Soft drum beat & $\begin{array}{l}\text { Panting sound as } \\
\text { wolf is seen }\end{array}$ & \\
\hline $\begin{array}{l}\text { Partially obscured } \\
\text { side view of wolf } \\
\text { quickly moving } \\
\text { from right to left, } \\
\text { then blinding } \\
\text { white light }\end{array}$ & & & $\begin{array}{l}\text { Snapping twigs as } \\
\text { wolf moves }\end{array}$ & \\
\hline \multirow{3}{*}{$\begin{array}{l}\text { Close-up soft focus } \\
\text { low-angle shot } \\
\text { in forest, a tree } \\
\text { branch vibrates as } \\
\text { if brushed against, } \\
\text { no sign of wolf }\end{array}$} & & & $\begin{array}{l}\text { Snapping twigs } \\
\text { again }\end{array}$ & \\
\hline & BY SIX & $\begin{array}{l}\text { a-flat" (C5), soft } \\
\text { drum beat }\end{array}$ & & \\
\hline & \begin{tabular}{|l|} 
BILLION \\
DOLLARS \\
\end{tabular} & $\begin{array}{l}\text { Louder drum beat } \\
\text { after "DOLLARS" }\end{array}$ & & \\
\hline $\begin{array}{l}\text { Close-up soft focus } \\
\text { shot of forest from } \\
\text { ground level, right } \\
\text { side obscured by } \\
\text { tree; on left of } \\
\text { screen, wolf moves } \\
\text { from right to left }\end{array}$ & & & $\begin{array}{l}\text { Low growl, rustling } \\
\text { branches or wind }\end{array}$ & \\
\hline
\end{tabular}


Article: Wolves at the door. Musical persuasion in a 2004 Bush-Cheney campaign advertisement

\begin{tabular}{|c|c|c|c|}
\hline $\begin{array}{l}\text { Brief close-up soft } \\
\text { focus shot of wolf } \\
\text { bounding into b/ } \\
\text { ground; camera } \\
\text { pans left }\end{array}$ & & & \\
\hline $\begin{array}{l}\text { Long shot pan } \\
\text { from right to left } \\
\text { onto hillside; in b/ } \\
\text { ground are gather- } \\
\text { ing storm clouds }\end{array}$ & & & \\
\hline Pan to left & & & $\begin{array}{l}\text { In white script, } \\
\text { all capital letters: } \\
\text { Kerry and the } \\
\text { liberals in Con- } \\
\text { gress: intelligence } \\
\text { cuts } \$ 6 \text { billion }\end{array}$ \\
\hline & & & $\begin{array}{l}\text { Beneath, in smaller } \\
\text { font: CQ Vote \#39, } \\
\text { ' } 94\end{array}$ \\
\hline & $\begin{array}{l}\text { CUTS SO DEEP, } \\
\text { THEY WOULD } \\
\text { HAVE WEAKENED }\end{array}$ & $c^{\prime \prime}(\mathrm{C5})$, drum beat & \\
\hline & AMERICA'S & drum beat & \\
\hline & DEFENSES & $f^{\prime \prime}(\mathrm{C} 5)$, drum beat & \\
\hline
\end{tabular}




\section{Ending}

\begin{tabular}{|c|c|c|c|c|}
\hline SHOTS & VOICEOVER & MUSIC & SOUND F/X & TEXT \\
\hline \multirow[t]{2}{*}{$\begin{array}{l}\text { Medium sharp focus shot } \\
\text { of grassy clearing on forest } \\
\text { edge; six wolves are sitting } \\
\text { or lying in semicircle facing } \\
\text { the camera; image framed } \\
\text { in black; next to text, small } \\
\text { picture of Bush }\end{array}$} & & & & $\begin{array}{l}\text { In white script } \\
\text { within black bar } \\
\text { in lower fifth of } \\
\text { screen in capital } \\
\text { letters: PAID } \\
\text { FOR BY BUSH- } \\
\text { CHENEY '04, } \\
\text { INC. AND THE } \\
\text { REPUBLICAN } \\
\text { NATIONAL } \\
\text { COMMIT- } \\
\text { TEE AND } \\
\text { APPROVED } \\
\text { BY PRESIDENT } \\
\text { BUSH }\end{array}$ \\
\hline & $\begin{array}{l}\text { AND } \\
\text { WEAKNESS } \\
\text { ATTRACTS } \\
\end{array}$ & Low rumbling & & $\begin{array}{l}\text { [TEXT VISIBLE } \\
\text { FOR REST OF } \\
\text { AD] }\end{array}$ \\
\hline \multirow{3}{*}{$\begin{array}{l}\text { Wolves rise and disperse, } \\
\text { with two coming toward } \\
\text { the camera }\end{array}$} & THOSE & & & \\
\hline & $\begin{array}{l}\text { WHO ARE } \\
\text { WAITING }\end{array}$ & $\begin{array}{l}\text { FRAMING: } \\
\text { Hollow flute } \\
\text { on middle C; } \\
\text { sforzando piano } \\
\text { tones F to B-flat } \\
\text { coordinated with } \\
\text { two loud drum } \\
\text { beats }\end{array}$ & Rustling grass & \\
\hline & $\begin{array}{l}\text { TO DO } \\
\text { AMERICA } \\
\text { HARM }\end{array}$ & $\begin{array}{l}\text { Flute chorus of } C \\
\text { and } F\end{array}$ & & \\
\hline Fade to black & & $\begin{array}{l}\text { Low flute A-flat } \\
\text { down to F, like } \\
\text { an echo; ad ends } \\
\text { with soft F minor } \\
\text { sonority }\end{array}$ & & \\
\hline $\begin{array}{l}\text { Fade in to Bush in his office, } \\
\text { wearing reading glasses } \\
\text { and on the telephone, with } \\
\text { papers and pen in his right } \\
\text { hand }\end{array}$ & $\begin{array}{l}\text { President Bush: } \\
\text { I'M GEORGE W. } \\
\text { BUSH, AND I } \\
\text { APPROVED THIS } \\
\text { MESSAGE }\end{array}$ & & & \\
\hline
\end{tabular}

* We use Helmholtz Pitch Notation to indicate the octave of each pitch.

The equivalent Scientific Pitch Notation follows in parentheses [e.g., g" (C5)]. 


\section{Beginning}

The impact of the aural introduction is powerful and immediate. Through a low, rumbling drone, primal drums, dissonance in shrill instruments, uncanny timbres, and more, music presents an enthymeme of fear and panic that audiences complete. The enthymeme is proposed by the music, which sets an ominous and frightful tone. To complete this complex enthymeme, audiences must complete three discrete tasks:

1. to connect music connoting horror to gradually unfolding images of wolves that represent a threat (or evil), and then,

2. to compare the wolves to terrorists, and finally,

3. to accept the proposition that with Kerry we are unsafe from terrorists (wolves), but with Bush we are safe.

Audiences are not supposed to realize that their fear comes from the music rather than from any rational argument.

How does the music convey fear? The opening frame presents a low $F$ drone in a flutelike timbre, combined with an explosive, attention-getting drum beat, followed by a softer drum beat. Setting the tone for what is to follow, this frame immediately evokes fear and unease. Taken with the intense and hushed voiceover and the confusing, mysterious images, which support the music's frame, the overall effect is chilling and foreboding.

Music frames and underscores the voiceover, helping to determine a fearful mood and to heighten it. The voiceover is particularly significant in the advertisement. Its syllabic stress-intonational speech emphasized by high volume or pitch relative to other syllables in a phrase-increases the prominence of certain words throughout the advertisement. The phrase "in an increasingly dangerous world" informs the audience of the context, and the trio of syllabically stressed words amplifies it. With "dangerous world," a shrill flute playing a $G$ is heard, and an F-B-flat leap in harp sounds on the phrase "after the first terrorist attack on America." The flute's underscoring - it is dissonant with the F fundamental tone and its timbre is strident-of "dangerous" startles the audience and augurs what is to follow. This underscoring also fixes dangerous in the audience's mind; this impression is visually complemented by a bright, blinding flash that immediately follows. A poetic interpretation might construe the underscored flute as an alarm whistle, alerting or foreshadowing danger and thus cuing suspense. Crucially, this also frames the Beginning's visual shift from clarity to disorientation.

A strong contrast between clarity and disorientation is developed through the advertisement's visual style. Clarity characterizes the Beginning and is visually constructed through relatively bright lighting; medium and long shot distances; lengthy shots; sharp and deep focus; and a stationary camera. Rather quickly, near the end of the Beginning, the visual clarity is obscured. The dissonant underscoring of the G against the lower F on "dangerous" cues the visual shift from clarity of vision to disorientation. 
The verbal discourse amplifies fear by reminding the audience of an earlier terrorist attack on the U.S. (presumably the 1993 World Trade Center bombing), and underscoring dictates affect. "After" in the phrase "after the first terrorist attack on America" receives strong syllabic stress and is underscored with an F-B-flat harp gesture, which also frames the fleeting shot of a wolf moving from right to left that follows. The verbal discourse sets up the advertisement's logical argument that Kerry and the liberals are reckless in their disregard for security. The advertisement implies that they ignored earlier evidence of a terrorist threat and thus allowed the $9 / 11$ attacks to occur.

Music facilitates the exchange between verbal and poetic discourses and the rhetorical argument that makes the advertisement an overdetermined persuasive pitch. Metaphors transform and translate complex entities into simple, primal things: threats/wolves and world/forest (Lakoff \& Johnson 1980). ${ }^{6}$ The wolves tap familiar narratives drawn from folk and fairy tales and a deep reservoir of difference between nature and culture. Wolves are "terrorists" of a different stripe, familiar to us in "Little Red Riding Hood" and "The Three Little Pigs." A familiar setting in such tales, the woods, underpins American foundational mythologies, such as the need to tame wild and threatening nature. The forest also serves as a metaphor for new 21st-century geopolitical configurations, such as the so-called global war on terror, and perhaps more generally the largely unknown world outside the "homeland." In the advertisement, the world is "increasingly dangerous." In narrative terms, these metaphors contribute to the characters and the setting.

In the poetic discourse, we become disoriented and vulnerable, moving from a position of power to one of weakness. The establishing shot over the forest signifies scopic power, but this feeling of visual dominion quickly wanes. By the fourth shot, our position is reversed-now we look up at trees from below. We have become disoriented and threatened prey. In the fifth shot, we see a wolf for the first time, but because it is so brief and the wolf is moving, we are not sure what we see. Retroactively -in the Middle segment-we realize what it was.

The poetic discourse includes elements of a generic horror plot. Carroll (1990) argues that horror plots include the following elements: onset, discovery, confirmation and confrontation (p. 99). "Wolves" contains the first three and implies the fourth. The Beginning provides the onset, where the "monster's presence [is] established" (Ibid.). It also shows us quickly becoming vulnerable. This segment establishes where we came from, and where we are now. We had dominion and clarity, but shortly afterward are plunged into the dark, disorienting woods, into a position of weakness and limited scope. We catch a glimpse of something moving near us. It is startling. We are not alone. ${ }^{8}$

Music frames and underscores the voiceover, images, and poetic discourse. We hear fear and dread and reconcile the images and voiceover with the musical connotations evoked by the horror genre framing. Music is the ringleader for the visual and poetic elements-significant images usually do not coincide with important musical events. That electronically 
generated sounds are used instead of acoustically produced ones adds to the advertisement's uncanny aspect.

Although they work together, musical frames in "Wolves" are clearly delineated from underscoring. They appear in the Beginning and Ending (exclusive of the disclaimer). Using the horror music genre, the musical frame determines how the advertisement will be interpreted. If we were to take away the music, there would be nothing frightening about the Beginning. But music is there to canalize the discourse, to imply danger and to establish fear that should impel us to action (voting). This musical frame is a striking, powerful appeal to fear-even after repeated hearings, it still does not fail to make the audience uneasy and inexplicably frightened (inexplicably, because this is a poetic appeal to emotion). The Beginning lasts a mere eight seconds, but in this brief period the entire framework is set for the rest of the advertisement.

\section{Middle}

Underscoring in "Wolves" is pointillistic. Through tiny musical gestures, carefully cued to voiceover and sound effects, a soundtrack of horror is created. The horror genre is a type of music that aims to not only create drama and suspense, but also a deep sense of unease and foreboding about the ineluctable and imminent occurrence of evil. "Wolves"' stylistic characteristics belong to a late twentieth-century horror or thriller films, such as the score to Michael Mann's 1986 film Manhunter. All of the musical elements can be found in such scores: whistles, hollow-sounding choral oohs, synthesized strings, irregular drum beats that sound like tribal war drums.

Underscoring likewise works somewhat like a film score: specific musical cues are timed to coincide with verbal events. The verbal discourse builds upon the characterization of growing threats (and the implication of Kerry's lack of concern), advancing it further by informing us that Kerry and the liberals wanted to cut intelligence funding. Audiences are likely to remember the claim through repeated exposure. Syllabic stress and underscoring undergird this claim: "John Kerry, liberals, Congress, slash, six billon dollars, cuts, deep, and weakened" are all emphasized. "Slash, six billion dollars, and weakened" receive the strongest stress. Furthering the emphasis on this information, this part of the advertisement is the most percussively underscored part of the voiceover. Carrying over from the Beginning, we hear underscoring with "John Kerry and the liberals in Congress": drum beats occur after "liberals and Congress" (here we see a wolf for the second time in the advertisement). A low drum beat is followed by another on "voted to slash". A soft drum beat underscores "America's intelligence operations" (here we get the only close-up of a wolf). Afterward, a soft and then loud drum beat on the phrase "by six billion dollars" coincide with A-flat. (The minor inflection's coinciding with "six billion dollars" illustrates how underscoring complements the verbal discourse.) And varied drum beats follow each word in the phrase "weakened (soft) America's (loud) defenses (soft)". This underscoring amplifies the voiceover stresses 
and adds gravity to the message. Three successive drum beats are heard, along with flute $C$ and F, on the phrase "cuts so deep, they would have weakened America's defenses".

Various musical components foreshadow how the Ending resolves the suspense initiated in the Beginning. The $F$ minor scale is gradually built throughout: first F, then $G$, followed by B-flat and C, and then the pentachord is filled in with A-flat on the phrase "by six billion dollars". In the subsequent phrases "cuts so deep, they would have weakened America's defenses", C and F complete the F minor chord.' (All of these tones are accompanied by drum beats powerfully punctuating the voiceover text.) The dark minor mode confirms the advertisement's ominous implication: we are vulnerable to imminent attack. Introduced in the Middle, the F minor sonority will be present in the Ending, as will the drum beats that have obsessively accented key voiceover words.

As mentioned earlier, since it is the music that determines the story, we only retrospectively understand the images as fitting into a poetic narrative; that is, the pictures follow the music. For this reason, the images do not follow the music note for note. Throughout the advertisement, we are visually trying to "catch up" with the connotations the music established at the very start. We hear disturbing music and we try to fit the images with the music to complete the enthymeme presented by the advertisement's creators. Increasing dissonance in the music is meant to determine the wolf as threatening (and, by extension, to exclude interpretations of wolves as neutral or benign).

The Middle is the most visually disorienting segment. The lighting in most shots is chiaroscuro, primarily dark, at times accentuated by brighter backlighting from the sun. ${ }^{10}$ Such lighting hinders visual clarity and complements the fearful mood established and forwarded by the music. Shot distances are close, creating a claustrophobic sense. Shot durations are very short, the bulk of the cuts occur here (10 out of 16), and the audience is unable to firmly situate their gaze and temporal grounding. Rapid cuts accelerate the pace of the advertisement, and contribute to increasing suspense. The shot focus is soft and fuzzy, and the camera moves a great deal, like a person searching. Visual disorientation begins to nudge the audience toward panic.

Our sense of disorientation and panic increases in this part of the poetic discourse. Significantly, we first unambiguously perceive a wolf, and get the only close-up shots of it. The horror plot further develops with onset (retroactively), discovery, and confirmation. Discovery is where we learn of the monster's existence (Carroll 1990, p. 100). Confirmation "involves the discoverers of or the believers in the existence of the monster convincing some other group of the existence of the creature" (Ibid., p. 101). These are achieved through increasing encounters with the wolf, and the voiceover information that implies Kerry is not amply concerned about these threats.

By the end of the segment, we are ready to protect ourselves from this existential threat. We know the world is dangerous, and we know the source. Our resolve is clear. This poetic knowledge complements the framing of Kerry and the liberals as feckless; we must look to others for security. At the end of the segment, our gaze moves into a clearing. 


\section{Ending}

In the final frame, numerous elements come together to bring closure. After the voiceover "who are waiting" (as the wolves arise), we hear a brief pause, a sort of musical colon, demanding that we pay close attention to what follows. Then there follows a sforzando F-B-flat piano figure, a hollow flute chorus on F and B-flat, and a low flute A-flat-F (like an echo). Here the F minor tonality, merely hinted at in the Middle, comes together most convincingly. Harmonically, dynamically, and timbrally, the music in the final seconds of the advertisement brings together all of the frightening and uncanny elements from the Beginning and Middle sections. While the Beginning frame was chilling, the Ending frame is harrowing and terrifying.

The verbal discourse links Kerry and the liberals with weakness, reinforcing the claim that their votes weakened America's defense. More importantly for the poetic discourse of the advertisement, an assertion that weakness entices terrorists to attack gives this information context. Strong syllabic stress is placed on: "Attracts, waiting, America harm". As in the Middle, the inflected words serve a mnemonic function; the message will resonate after details are forgotten. Music again frames and underscores the verbal. The most powerful stress of the whole advertisement is on "waiting". The word is emphasized musically (flutes and drum beats) and by the ensuing stark silence. The word is pregnant with meaning: the U.S. could be attacked at any moment. This is the climax of the advertisement. The phrase "America harm" is framed by a middle range flute A-flat and $\mathrm{F}$ that punctuates it at the very end (exclusive of the disclaimer). Intense but quiet dissonance completes the framing.

In the Ending, visual clarity is restored (we are prepared for it as the Middle ends with a shot of a clearing). The first shot shows wolves assembled in another clearing facing us. The wolves are at eye level, brightly and evenly lit and in sharp focus. We clearly face not one wolf, but a pack, a "gathering threat," as Bush described Saddam Hussein prior to the 2003 invasion. The wolves rise and disperse as the verbal and poetic discourses close. We wonder where they are going. At the end, the loud sforzando can be perceived poetically as a terrorist attack; the successive static, hissing sound can seem like the aftermath and shock that follow the attack.

The audience's position as prey is evident in the Ending, with wolves dispersing after waiting. The advertisement's denouement completes the confirmation, and implies an inevitable confrontation with the wolves (monsters). The wolves coming toward us invite confrontation, as does the implied message of the difference between Kerry and Bush. Implied confrontation is another persuasive message advanced poetically that complements verbal framing forwarded by the Bush campaign (but not explicitly articulated in "Wolves"): The U.S. must be on the offensive.

The Ending draws together all of the segments effectively. Like the Beginning, things are clearer, although we are not out of the woods yet. We've been thrust into disorienting, dangerous woods in which stealthy threats are within earshot. Some authorities are weak and their actions (or inaction) endanger us. Worse yet, weakness attracts the wolves, which 
are gathering to do us harm. We are primed for assertive security. We are left to complete the enthymeme, to infer the message of the parable. ${ }^{11}$ We need strong authorities to protect us, authorities who understand the dangerous woods and the threatening wolves within.

Taken together, the Beginning and Ending frames respectively establish and then confirm an overarching sense of dread and terror. It is only through the lens of the musical frame that we see the wolves as the collective threat that the advertisement's creators want us to perceive. Without music the advertisement is simply a series of confusing images of the forest and of one wolf and subsequently six wolves, along with the voiceover, and it would strike the audiences as absurd and nonsensical in the extreme. Every other element of the advertisement hearkens to the music; pictures and words dance to the music's tune, not the other way around. So, far from mere innocuous accompaniment to a rhetorical argument, music is the lynchpin for the entire advertisement.

\section{The Coda}

In the form of a disclaimer that comports with campaign finance regulations, the advertisement's coda provides resolution for the enthymeme. The disclaimer depicts Bush wearing reading glasses and speaking on the telephone, holding papers and a pen. He appears to be hard at work. Visually, the disclaimer formally mirrors the Ending. It is brightly lit, the camera is stationary, and the muted colors carry over. The images of the threatening wolves are answered by the image of Bush working, comfort after the fear conjured by the advertisement. Bush's voiceover- "I'm George W. Bush and I approved this message"-ascribes authorship and offers reassurance. While the disclaimer lacks music, the closing music in the Ending and the pregnant pause after waiting resonate here: the suspense finds resolution in the coda. Throughout the entire advertisement, music generates a frightening mood, and the disclaimer portrays Bush as superior to Kerry, as he clearly sees the threats and is acting to confront them. ${ }^{12}$

Bush's voiceover also serves to contrast the coda with the rest of the advertisement, through the formal separation that the disclaimer provides. The texture of Bush's voice is nearly the opposite of the female narrator. Rather than hushed, Bush's words are delivered at a moderate, conversational volume. Instead of intimate, Bush's voiceover is jocular-gregarious in the fashion of a salesperson or corporate spokesperson. Bush's voice lacks the narrator's breathy qualities. He speaks crisply. And relative to the range for his gender, Bush's voice is not nearly as deep as the narrator's. But the biggest contrast lies in the accents. The narrator's accent belies no regional, ethnic or class coloring. It is the epitome of a standard American English broadcast accent. Bush of course is known for his Southern accent, which is amply articulated in his voiceover. ${ }^{13}$ Furthermore, unlike the narrator Bush is embodiedwe see him as the voiceover is heard. Unlike the narrator whose voiceover functions to seduce and scare us, Bush's voiceover works to comfort us. 


\section{Voiceover}

Gender is a key characteristic of the voiceover and its effect on us; it evokes the uncanny. ${ }^{14}$ For Freud (1955), the unheimlich (uncanny) is an impression associated with things simultaneously familiar and strange. The advertisement's voiceover is uncanny owing to its gender and disembodiment. Gender is at the core of Freud's conceptualization of the uncanny. The ultimate source of the uncanny is woman, more specifically the vagina and womb. They are familiar in that we biologically originate from them, and strange owing to our identification with the phallus (Freud 1955).

Disembodied female voices in radio and audiovisual texts are especially uncanny for audiences who are used to also seeing women's bodies on TV or in films. Historically, film and TV rarely use disembodied female voices, and when they do they nearly always embody them at some point. Film scholar Kaja Silverman (1988) claims that this representational convention is tied to the practice of constructing women as spectacular objects. ${ }^{15}$ Lacking body, a female voiceover violates expectations of the familiar-a spectacular female body - therefore suggesting an absent presence that evokes the uncanny. Similarly, a female announcer can signify the "weaker sex," which may work to intimate vulnerability. Such familiar gender connotations may appeal to conservative voters and resonate with their perception of "traditional" gender roles and difference. The narrator might conjure the patriarchal ideal of home/heimlich (and its associated term in this context, the homeland), as well as the threats to it the advertisement invokes-the unheimlich manifested in the wolves. ${ }^{16}$ Furthermore, because the voiceover lacks a visible body, it is perceived to have greater power than an embodied voice. Michel Chion argues that disembodied voices in film are perceived as ubiquitous, panoptic, omniscient, and omnipotent, qualities ascribed to supernatural or divine entities (1999, p. 24).

Likewise important is the narrator's vocal texture. Her vocal timbre furnishes the verbal discourse with substance and seriousness. A hushed delivery conveys an aural presence and proximity that complement the poetic narrative; above all the voice is intimate. Indeed, its intimacy borders on the seductive because of its near-whispered delivery, rather deep tones, and breathy qualities. Our perception of the words is colored by the voice's textures, presence, and intimate huskiness that suggest a "bedroom voice."17 The seductive qualities of the voice inflect the verbal discourse-its intimacy invites receptiveness. Though we may not agree with the verbal discourse, its sybaritic qualities persuade us to listen. The poetic character of the voice functions to facilitate its logical content.

Furthermore, the voice serves another aspect of the advertisement's poetic discourse: to make us feel threatened. The voiceover's qualities are firmly denoted by the music and articulated with the advertisement's visual elements. While the voice connotes sensuality, the advertisement's visual iconography and musical underscoring convey concern and alarm. As it does with the denotation of the advertisement's images, music determines the possible meanings of the voiceover-it instructs us how to hear it. The music and voiceover color the advertisement's soundscape and images with an unambiguous sense of forebod- 
ing and darkness. ${ }^{18}$ Although the voice functions to deliver the logical discourse, it is also sonically pleasurable. But the voice also works in conjunction with the music to facilitate the poetic discourse-we are threatened by stealthy, shadowy creatures. The voiceover seduces us to listen, and the experience is simultaneously sensual and unnerving.

\section{Conclusions}

Comprehended as a whole, this advertisement carefully constructs an enthymeme as outlined above; its main point is that serious threats imperil America and that Kerry and the liberals are too weak to effectively address them. Though a solution is not explicitly offered, it is strongly implied by the disclaimer. We are rhetorically nudged toward comparing Kerry unfavorably to Bush. Of course, such contrasts are always implied in negative advertisements, but "Wolves" uses the disclaimer determinatively to highlight the contrast. The audience is guided to complete the enthymeme by concluding that Bush will save us from unknown and ever-present terrors. "Wolves" is so effective because it uses clear and well-established imagery and it requires the audience to participate in the construction of meaning.

Music in "Wolves" is meant to be felt rather than heard-let alone analyzed. Electronically generated sounds distance the music from attempts at analysis, and the overall effect is surreptitious. The climax at the voiceover word "waiting" brings the advertisement together, where the music is loudest and most suspenseful. "Waiting" is punctuated by a loud, dissonant chord followed by silence that primes the audience for the chilling four-word tagline: to do America harm. The narrator's ominous tone and the images of scattering wolves that ensue together create a powerful call-to-arms that we are compelled to heed.

Ultimately, understanding how music works in political advertisements is key to arming ourselves against its powerful capacity to propagandize or persuade. Music is increasingly being marshaled as a means of persuasion-83 percent of campaign advertisements in the 2000 campaigns used music (Brader 2006, p. 157). Often, even in the absence of logically sound and reasoned argument, music in advertisements can bear the rhetorical cargo. Even those of us who regularly study music's ability to persuade are astonished by our inability to divorce ourselves from its impact, despite our conscious awareness of its force. We must disabuse ourselves of the untenable perception of music as non-discursive and attend to its poetic conscription for propaganda and persuasion. The more we are aware of music's hidden potency, the less it will work its magic unchecked. No less than our popular sovereignty is at stake. An educated and critically engaged electorate is necessary for a properly functioning democracy, and the public should be conscious of how campaigns attempt to manipulate them with music. 


\section{References}

Berger, A.A. (1992). Popular Culture Genres. Thousand Oaks, CA: Sage.

Birnbaum, J.H. \& Edsall, T.B. (2004, 6 November). At the end, pro-GOP 527s outspent their counterparts.

The Washington Post. Consulted on: 24 February 2011, Proquest Newspapers database.

Brader, T. (2006). Campaigning for Hearts and Minds. Chicago: University of Chicago Press.

Carroll, N. (1990). The Philosophy of Horror. New York: Routledge.

Chion, M. (1999). The Voice in Cinema. Translated by C. Gorbman. New York: Columbia University Press.

Cook, N. (1998). Analysing Musical Multimedia. Oxford: Oxford University Press.

Dennis, D.B. (2002). 'Honor Your German masters': The use and abuse of 'classical' composers in Nazi propaganda. Journal of Political and Military Sociology, 30 (2), 273-95.

Devlin, L.P. (2005). Contrasts in presidential campaign commercials of 2004. American Behavioral Scientist, 49, 279-313.

Edmunds, N. (ed.). (2004). Soviet Music and Society under Lenin and Stalin: The Baton and Sickle. New York: Routledge.

Frank, T.C. (1997). The Conquest of Cool. Chicago: University of Chicago Press.

Freud, S. (1955). The uncanny. In J Strachey (ed.), The Standard Edition of the Complete Psychological Works of Sigmund Freud (pp. 217-255). London: Hogarth Press.

Graakjær, N.J. (2006). Musical meaning in TV-commercials: A case of cheesy music. Popular Musicology Online, 5. Retrieved February 24, 2011 from http://www.popular-musicology-online.com/issues/05/ nicolai-01.html.

Hanley, J.J. (2004). 'The land of rape and honey': The use of World War II propaganda in the music videos of Ministry and Laibach. American Music, 22 (1), 158-75.

Huron, D. (1989). Music in advertising: An analytic paradigm. Musical Quarterly, 73, 557-574.

The Hotline. (2004, 27 October). Apathy? Go with it. Consulted on: 24 February 24 2011, Proquest Newspapers database.

The Hotline. (2004a, 25 October). Bush: jittery? Consulted on: 24 February 2011, Proquest Newspapers database.

Jamieson, K.H. (ed.) (2006). Electing the President 2004. Philadelphia: University of Pennsylvania Press.

Jhally, S. (1990). The Codes of Advertising. New York: Routledge.

Jowett, G.S. \& O'Donnell, V. (2006). Propaganda and Persuasion, $4^{\text {th }}$ ed. Thousand Oaks, CA: Sage.

Kaid, L.L. (2005). Videostyle in the 2004 presidential advertising, In R.E. Denton Jr. (ed.), The 2004 Presidential Campaign (pp. 283-299). Lanham, MD: Rowman \& Littlefield.

Klein, N. (1999). No Logo. New York: Picador.

Krumhansl, C.L. (1997). An exploratory study of musical emotions and psychophysiology. Canadian Journal of Experimental Psychology, 51, 336-52.

Lakoff, G. (2004). Don't Think of an Elephant! White River Junction, VT: Chelsea Green.

Lakoff, G. \& Johnson, M. (1980). Metaphors We Live By. Chicago: University of Chicago Press.

McCracken, A. (2002). Scary women and scarred men. In M. Hilmes \& J. Loviglio (eds.), Radio Reader (pp. 183-207). New York: Routledge.

Montgomery, D. (2004, 29 October). Experts say fear-mongering making this the ugliest election in memory. Fort Worth Star-Telegram. Consulted on: 24 February 2011, Proquest Newspapers database.

Nelson, J.S. \& Boynton, G.R. (1997). Video Rhetorics. Urbana, IL: University of Illinois Press.

Oettinger, R.W. (2001). Music as Propaganda in the German Reformation. Aldershot, UK: Ashgate.

Perris, A. (1985). Music as Propaganda: Art to Persuade, Art to Control. Westport, CT: Greenwood Press.

Potter, P. (1998). Most German of the Arts: Musicology and Society from the Weimar Republic to the End of Hitler's Reich. New Haven: Yale University Press. 
Pratkanis, A.R. \& Aronson, E. (2001). Age of Propaganda, rev. ed. New York: W.H. Freeman.

Richardson, G.W. (2003). Pulp Politics. Lanham, MD: Rowman \& Littlefield.

Rikard, D. (2004). Patriotism, propaganda, parody, and protest: The music of three American wars. Literature \& the Arts: An International Journal of the Humanities, 16 (1-2), 129-44.

Robinson, J. (2005). Deeper Than Reason: Emotion and its Role in Literature, Music, and Art. Oxford: Clarendon Press.

Schneider, H. (1992). The sung constitutions of 1792: An essay on propaganda in the revolutionary song. In M. Boyd (ed.), Music and the French Revolution (pp. 236-75). Cambridge: Cambridge University Press.

Sheppard, W.A. (2001). An exotic enemy: Anti-Japanese musical propaganda in World War II Hollywood. Journal of the American Musicological Society, 54 (2), 303-57.

Silverman, K. (1988). The Acoustic Mirror. Bloomington, IN: Indiana University Press.

Sproule, J.M. (1994). Channels of Propaganda. Bloomington, IN: EDINFO Press.

Stilwell, R.J. \& Powrie, P. (eds.). (2008). Composing for the Screen in Germany and the USSR: Cultural Politics and Propaganda. Bloomington, IN: Indiana University Press.

Tan, S.E. (2005). Manufacturing and consuming culture: Fakesong in Singapore. Ethnomusicology Forum, 14 (1), 83-106.

Tellis, G. (2003). Effective Advertising. Thousand Oaks, CA: Sage.

Trainor, L.J. \& Schmidt, L.A. (2003). Processing emotions induced by music. In I. Peretz \& R. Zatorre (eds.), The Cognitive Neuroscience of Music (pp. 310-324). Oxford: Oxford University Press.

Volker, R. (2008). Herbert Windt's film music to Triumph of the Will: Ersatz Wagner or incidental music to the ultimate Nazi-Gesamtkunstwerk? In R.J. Stilwell \& P. Powrie (eds.), Composing for the Screen in Germany and the USSR: Cultural Politics and Propaganda (pp. 39-53). Bloomington, IN: Indiana University Press.

Williams, R. (1977). Marxism and Literature. Oxford: Oxford University Press.

\section{Notes}

1. For their valuable insights and thought-provoking comments, the authors wish to thank the anonymous reviewers of this journal.

2. The advertisement is available at: http://www.livingroomcandidate.org/commercials/2004.

3. Post-election surveys found "Wolves" to be one of the most effective and influential advertisements of the campaign (Kaid 2005, p. 296). Of all the advertisements aired in important battleground states, "Wolves" was the only one to have high, unaided recall (Devlin 2005, p. 287). It was also ranked the third-most influential advertisement in battleground states by Public Opinion Strategies (Birnbaum \& Edsall 2004).

4. Additional explanation for how fear is processed in the brain can be found in Robinson (2005, pp. 47-52) and Trainor \& Schmidt (2003).

5. Sometimes a lack of music and other ambient sound can be just as effective: Pat LaMarche's spots in the 2006 gubernatorial election in Maine used silence with a black screen and white text questioning the necessity of the Iraq War in order to generate a mournful atmosphere for the fallen.

6. Bush media consultant Alex Castellanos produced the advertisement and based it on "a metaphysical idea that would represent the threat of the war on terror....when we tested 'Wolves,' people got it immediately. 'Wolves, terrorists, we got it, threat, yep'" (Jamieson 2006, p. 49).

7. Castellanos summarized the advertisement as: "Terrorists were wolves, renegades, chaotic and unpredictable enemies that lurked in the shadows and could strike any moment" (Jamieson 2006, p. 83). 
8. That we are not alone we suspect when we hear leaves rustling and twigs snapping. Music directly influences our emotions through the amygdala, which receives signals directly from the auditory thalamus. This is crucial to understanding how music acts on our emotions. Thus, the music in "Wolves" achieves its fear effect without initially engaging the reasoning part of our brain, the cerebral cortex. Joseph LeDoux gives an example of how the cortex determines ex post facto whether we should react to a stimulus or not: "Imagine walking in the woods. A crackling sound occurs. It goes straight to the amygdala through the thalamic pathway. The sound also goes from the thalamus to the cortex, which recognizes the sound to be a dry twig that snapped under the weight of your boot, or that of a rattlesnake shaking its tail. But by the time the cortex has figured this out, the amygdala is already starting to defend against the snake. The information received from the thalamus is unfiltered and biased toward evoking responses" (quoted in Robinson 2005, p. 50).

9. The notes $D$ and $E$ (as well as their natural minor counterparts $D$-flat and $E$-flat) are absent in this advertisement, so we can only speak of the $F$ minor pentachord of F, G, A-flat, B-flat, and C.

10. According to Castellanos, the sky in the establishing shots was darkened, "to portend the gathering storm and [we] darkened the rest of the shots" to enhance the perception of a "dark moment before a terrorist attack" (Jamieson 2006, p. 83).

11. Castellanos said the last shot was constructed to be open-ended and provocatively suggestive. "The wolves are going somewhere. Where are they going and why? I wanted to leave the end of the spot inconclusive" (Jamieson 2006, p. 83).

12. Likewise, the disclaimer's positioning differs from other Bush advertisements. According to Bush campaign media consultant Alex Castellanos, where to place the legal disclaimer-at the beginning or ending - was contentious within the campaign. Castellanos thought the disclaimer should come at the beginning, believing that such placement is more effective in advertisements that appeal to emotion (Jamieson 2006, p. 82).

13. Bush's voice also contrasts a great deal with John Kerry's. Although both men are the descendants of elite, New England families (Bush was born in New Haven, Connecticut), and attended Ivy League schools, their accents and diction connote great difference. We note suggestive similarities between this performative difference, and the ways music works in political advertisements. Logically, Bush and Kerry are quite similar, but their personas poetically convey difference.

14. In his analysis of campaign advertisements from the year 2000, Brader (2006) found that female narrators were used in fear advertisements by a two-to-one margin (p. 163).

15. Radio is somewhat of an exception, as it is a sonic medium that formally disembodies voices. Nevertheless, disembodied female voices on the radio retain an element of the uncanny owing to prevailing media conventions. As McCracken (2002) notes, disembodied female voices provided particularly uncanny and suspenseful affect in radio thrillers and mysteries.

16. The use of a female announcer was strategic, too. The campaign constructed and refined the advertisement to appeal to women 35 and older, and focus groups showed women responded more strongly than men (Jamieson 2006, p. 83).

17. The authors would like to thank an anonymous reviewer of this article for the apt description of "bedroom voice" to characterize the narrator's vocal texture.

18. While the narrator has a distinct voice, she is anonymous as in all of Bush's attack advertisements. In contrast, Kerry made the attack in thirty percent of his advertisements (Kaid 2005, p. 289). 
Article: Wolves at the door. Musical persuasion in a 2004 Bush-Cheney campaign advertisement

Matthew Killmeier, Ph.D.

Assistant Professor

Department of Communication and Media Studies

University of Southern Maine, United States

mkillmeier@usm.maine.edu

Paul Christiansen, Ph.D.

Assistant Professor

School of Music

University of Southern Maine, United States

pchristiansen@usm.maine.edu 